\title{
Selective Oxidation during the Austenitic Annealing of a CMnSi Steel
}

\author{
T. Van De Putte ${ }^{1, a}$, Z. Zermout ${ }^{2, b}$, D. Loison ${ }^{3, c}$, S. Claessens ${ }^{2, d}$, J. Penning ${ }^{1, e}$ \\ ${ }^{1}$ Department of Metallurgy and Materials Science, Ghent University, Technologiepark 903, \\ B-9052 Zwijnaarde, Belgium \\ Tel.: ++32 (0)9 26457 61, Fax: ++32 (0)9 2645833
}

${ }^{2}$ Industry Research Centre Gent - OCAS NV - ARCELOR, J. Kennedylaan 3, B-9060

Zelzate, Belgium Tel.: ++32 (0)9 34513 66, Fax: ++32 (0)9 3451204

${ }^{3}$ Arcelor Research SA, Voie Romaine, BP30320, F 57283, Maizières-les-Metz, France Tel. : +33 (0)3 87704720

\section{E-mail: aTom.VanDePutte@Ugent.be, ${ }^{b}$ Zinedine.Zermout@arcelor.com , cDidier.loison@arcelor.com, '`Serge.Claessens@arcelor.com, Jan.Penning@Ugent.be}

Keywords: Selective oxidation, XPS, Surface state, Austenite

\begin{abstract}
High strength multiphase CMnSi steel is increasingly used in passenger cars. Si and Mn alloying levels are typically in the range of $1-2 \%$ in mass. While Si improves the mechanical properties, it considerably deteriorates the galvanisability of steel. Residual water vapour in the reducing gas atmosphere during the intercritical or austenitic annealing results in the selective oxidation of Si and $\mathrm{Mn}$ at the steel surface. Besides $\mathrm{Mn}$ and $\mathrm{Si}, \mathrm{C}$ is oxidized as well at the steel surface, leading to the formation of $\mathrm{CO}$ gas and decarburisation of the steel surface. This decarburisation has a major influence on the phase composition in the steel surface region: it shifts the ferrite to austenite transformation to higher annealing temperatures, leading to differences in surface and bulk microstructure. The phase composition influences the solubility and diffusivity of all alloying elements near the surface. The evolution with temperature of the selective oxidation at the steel surface has been studied by interrupted annealing in a protective atmosphere containing residual water vapour. The influence of the annealing temperature on the selective oxidation of $\mathrm{Mn}$ and $\mathrm{Si}$ is characterized by XPS (X-ray Photo-electron Spectroscopy) analysis.
\end{abstract}

\section{Introduction}

It is known that for a good quality hot dip galvanising, an appropriate concentration of metallic iron at the steel surface is necessary to allow the formation of an inhibition layer by reaction between the substrate iron and $\mathrm{Al}$ in the zinc bath. It is proved that selective surface oxidation during recrystallization annealing considerably hampers the galvanisability $[1,2,3,4]$.

Surface selective oxidation of a Si and Mn alloyed high strength steel has already been studied in various conditions [5] but not yet thoroughly during austenitic annealing.

Previously it was shown by Mahieu [6] that there is less external selective oxidation on a CMnSi steel composition provided that the temperature is high enough to ensure a fully austenitic annealing. Due to the high carbon content the studied high strength steels however, the decarburization of the surface region during annealing has to be considered. The carbon depletion near the surface will cause the austenitisation to move up to higher temperatures. That might explain the large difference in oxidation behaviour for isothermal annealing at $850^{\circ} \mathrm{C}$ and $950^{\circ} \mathrm{C}$ despite the fact that the equilibrium bulk phase is austenite from $845^{\circ} \mathrm{C}$ on.

The results presented in this paper are part of the continuation of the research of Mahieu. The purpose of this study is to make a confirmation of what was earlier reported and to formulate an explaining hypothesis. 


\section{Experimental}

The chemical compositions of the steels used in this work are presented in Table 1. The first is a laboratory casting, the second one is an industrial steel supplied by Arcelor.

Table 1: Chemical compositions of the steels used in this work (concentrations in wt\%).

\begin{tabular}{|l|c|c|c|c|c|}
\hline Material & $\mathrm{C}$ & $\mathrm{Mn}$ & $\mathrm{Si}$ & $\mathrm{Al}$ & $\mathrm{P}$ \\
\hline Laboratory steel & 0.25 & 1.69 & 1.28 & 0.06 & 0.015 \\
Industrial steel & 0.2 & 1.6 & 1.6 & 0.04 & 0.012 \\
\hline
\end{tabular}

The surfaces of the cold rolled steel sheets (thickness $1 \mathrm{~mm}$ ) were all grinded and mirror polished before the recrystallization annealing in order to remove all influences of the steel processing. It can thus be assumed that before annealing the surface and bulk properties are identical.

Small circular (10mm in diameter) samples are then punched out of the polished steel sheet and heat treated in a $\mathrm{N}_{2}-5 \% \mathrm{H}_{2}$ atmosphere with a dew point of $-50^{\circ} \mathrm{C}$. The heat treatments are performed in an infrared furnace directly connected to the XPS analysis chamber, providing a pseudo in-situ XPS characterization of the annealed samples. The two types of annealing cycles used in this study are represented in Figure 1. The laboratory steel was rapidly heated and maintained for 2 minutes at either $850^{\circ} \mathrm{C}$ or $950^{\circ} \mathrm{C}$ for 2 minutes, followed by a natural cooling in low vacuum (1 mbar) to prevent oxidation during cooling. The selection of the soaking temperatures is based on the earlier study of Mahieu [6]. The theoretical austenitisation temperature calculated by ThermoCalc software for the laboratory steel is $845^{\circ} \mathrm{C}$, meaning that the equilibrium phase for both temperatures is austenite. For the industrial alloy an interrupted annealing with low heating speed $\left(6^{\circ} \mathrm{C} / \mathrm{s}\right)$ was chosen: samples were heated to different temperatures from $450^{\circ} \mathrm{C}$ to $1000^{\circ} \mathrm{C}$ and naturally cooled down in a low vacuum without soaking. The purpose of these annealing tests is to evaluate the evolution of the selective oxidation of the surface during the heating section of the continuous annealing process. The choice of a different annealing cycle for the two steels has no scientific reason.
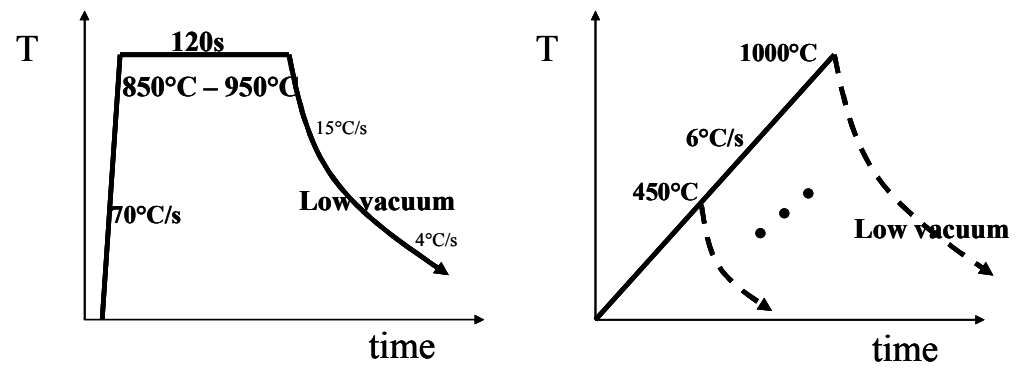

Figure 1: schematic representation of the used annealing cycles in a temperature versus time graph. Left the isothermal annealing cycle and on the right hand side the interrupted heating treatment.

Directly after annealing, the samples are transferred under high vacuum $\left(10^{-9} \mathrm{mbar}\right)$ to a XPS analyzer. XPS measurements were carried out on a Microlab 320-D from Fisons/VG Scientific with a non monochromatic $\mathrm{AlK}_{\alpha}$ anode and a take off angle of $90^{\circ}$. Analysis quantification was based on sensitivity coefficients proposed by the manufacturer. After this first analysis, some samples are exposed to ambient air for about 2 minutes and are then analyzed again. Metallic iron at the steel surface after annealing will hereby be oxidized. The metallic iron underneath an oxide layer will be protected from the high oxygen partial pressure and will remain metallic. This procedure allows distinguishing between oxidizable metallic iron present at the surface and metallic iron located underneath a thin oxide layer. For galvanising, only the metallic iron available at the steel surface will be able to react with $\mathrm{Al}$ in the zinc bath to form the inhibition layer necessary for good quality galvanising.

The surface of the annealed samples is afterwards studied by FEG (Field Emission Gun) SEM secondary electron (SE) imaging and EDX (Energy Dispersive X-ray) analysis. A primary accelerating voltage of $5 \mathrm{keV}$ has been used to enhance surface sensitivity. 


\section{Results}

High heating rate isothermal annealing

The remarkable difference in oxidation state of the surface after isothermal annealing at $850^{\circ} \mathrm{C}$ and $950^{\circ} \mathrm{C}$, previously observed by Mahieu [6], could be confirmed. Figure 2 shows the XPS-spectra of $\mathrm{Fe}, \mathrm{Mn}$ and Si before and after air exposure. The results of the quantification of these spectra are presented in Table 2. For quantification the sum of the concentrations of the elements $\mathrm{Fe}, \mathrm{Mn}, \mathrm{Si}, \mathrm{C}$ and $\mathrm{O}$ was normalized to $100 \%$. The drop in total iron content after air exposure is due to a higher oxygen concentration in the second analysis. The variations in concentration of $\mathrm{Si}$ and $\mathrm{Mn}$ after exposure are attributed to a statistical deviation in the spectrum acquisition.
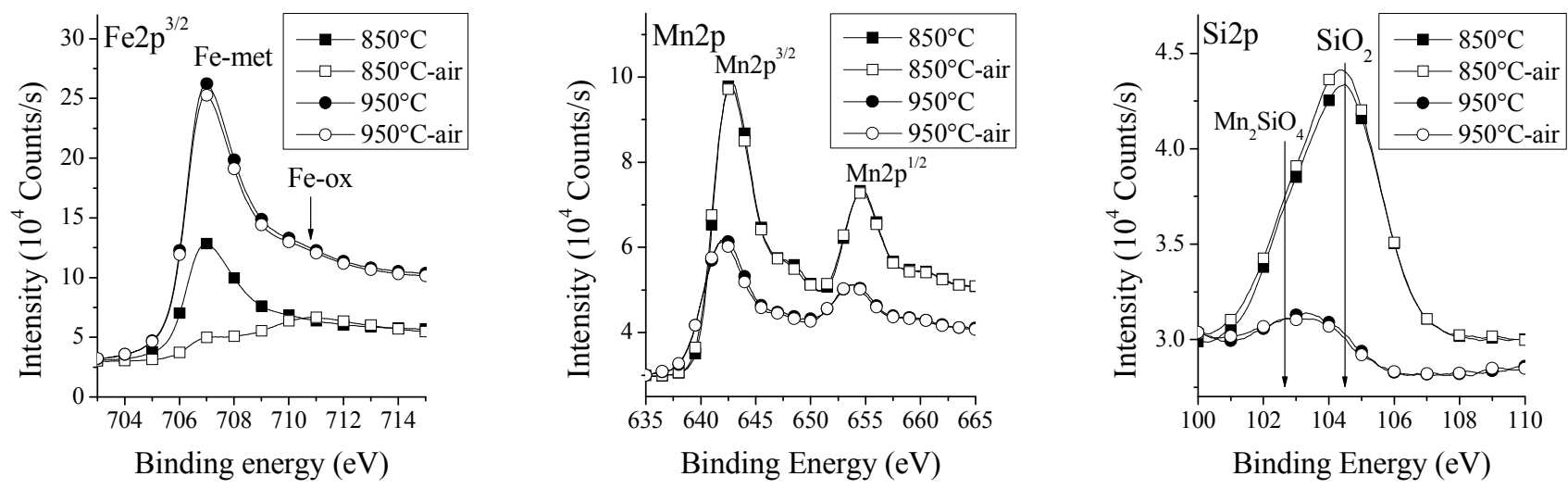

Figure 2: The Fe, Mn and Si XPS spectra of samples annealed at $850^{\circ} \mathrm{C}$ and $950^{\circ} \mathrm{C}$ for 120 s, before and after air exposure (air). Annealing was performed in $\mathrm{N}_{2}-5 \% \mathrm{H}_{2}$ with a dew point of $-50^{\circ} \mathrm{C}$.

After annealing at $950^{\circ} \mathrm{C}$ in a $\mathrm{N}_{2}-5 \% \mathrm{H}_{2}$ atmosphere with a dew point of $-50^{\circ} \mathrm{C}$, the steel surface seems to be less oxidized than after annealing at $850^{\circ} \mathrm{C}$ : there is much more metallic iron present near the surface. Nevertheless none of this metallic iron is oxidizable: the XPS spectra before and after air exposure are almost identical which indicates that the surface composition and oxidation state have not changed. This means that after annealing at $950^{\circ} \mathrm{C}$ the steel surface is covered with a very thin and continuous oxide layer, protecting the metallic iron underneath. This oxide layer can not be thicker than a few nanometer because a large amount of the underlying metallic iron is still detected by XPS. Although not presented, an Al peak was detected in the XPS spectra after annealing at $950^{\circ} \mathrm{C}$. It is known that $\mathrm{Al}$ strongly segregates to the steel surface at very low dew points [3]. So even while its bulk concentration is very low, Al can participate in the covering oxide layer by formation of $\mathrm{Al}_{2} \mathrm{O}_{3}$ or $\mathrm{Al}$ spinel oxides. However the continuity, thickness and composition of this layer are not yet verified by TEM analysis and sputtering techniques.

Table 2: Quantification results of the XPS spectra in Figure 2.

\begin{tabular}{|l|c|c|c|c|}
\hline & $\mathrm{Fe}_{\mathrm{met}}[\mathrm{at} \%]$ & $\mathrm{Fe}_{\mathrm{ox}}[\mathrm{at} \%]$ & $\mathrm{Mn}[\mathrm{at} \%]$ & $\mathrm{Si}[\mathrm{at} \%]$ \\
\hline $850^{\circ} \mathrm{C}$ & 7.3 & 1.2 & 10.0 & 18.0 \\
$850^{\circ} \mathrm{C}$-air & 0.7 & 3.6 & 9.1 & 17.3 \\
$950^{\circ} \mathrm{C}$ & 26.5 & 6.3 & 8.2 & 5 \\
$950^{\circ} \mathrm{C}$-air & 24 & 6 & 8 & 5.3 \\
\hline
\end{tabular}

After annealing at $850^{\circ} \mathrm{C}$, nearly all metallic iron present near the surface is oxidizable. Nevertheless the iron concentration is very small and will probably be insufficient for a good wettability on galvanising.

The peak heights and positions of the alloying elements have also changed with the annealing temperature. The binding energy of the $\mathrm{Mn} 2 \mathrm{p}^{3 / 2}$ electrons is about $641.8 \mathrm{eV}$ and $642.7 \mathrm{eV}$ for annealing at $950^{\circ} \mathrm{C}$ and $850^{\circ} \mathrm{C}$ respectively. The Si2p peaks have 2 constituents at $102.7 \mathrm{eV}$ and $104.5 \mathrm{eV}$, respectively corresponding to $\mathrm{Mn}_{2} \mathrm{SiO}_{4}$ and $\mathrm{SiO}_{2}$ [7]. After annealing at $850^{\circ} \mathrm{C}$, the main peak corresponds to $\mathrm{SiO}_{2}$ while at $950^{\circ} \mathrm{C}$ he corresponds to $\mathrm{Mn}_{2} \mathrm{SiO}_{4}$. 
After annealing in the reducing atmosphere, a part the detected iron atoms are oxidized. This can be due to the substitution of $\mathrm{Mn}$ with iron atoms in $\mathrm{Mn}_{2} \mathrm{SiO}_{4}$ or due to low temperature iron oxidation during cooling $[4,7]$.

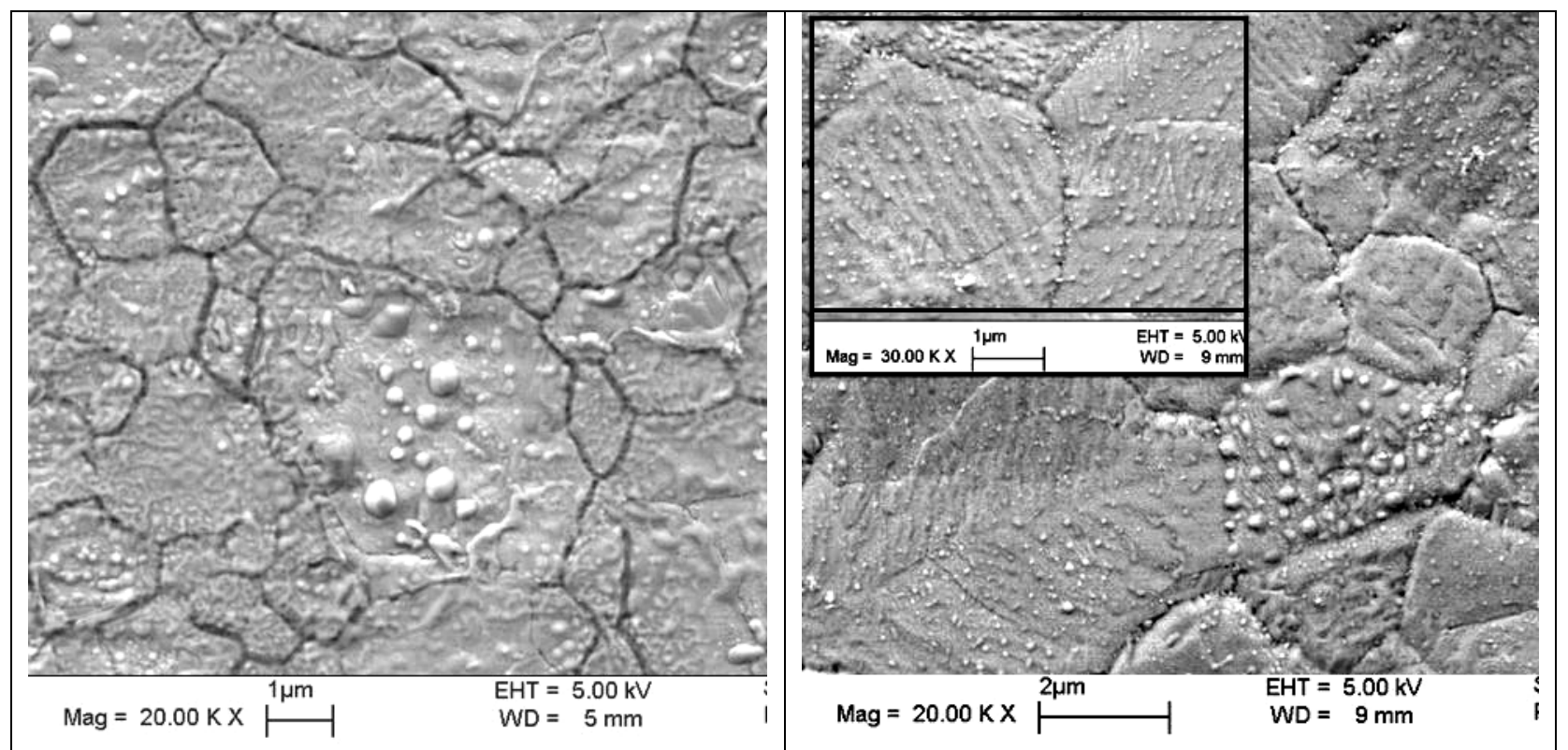

Figure 3: SEM SE (Secondary Electron) images of the surface of the laboratory steel after annealing for 2 minutes at $850^{\circ} \mathrm{C}$ (left) and $950^{\circ} \mathrm{C}$ (right). Annealing at $850^{\circ} \mathrm{C}$ results in a severely oxidized surface covered with a $\mathrm{SiO}_{2}$ film and lenticular $\mathrm{Mn}_{2} \mathrm{SiO}_{4}$ oxides. After annealing at $950^{\circ} \mathrm{C}$ the surface seems to be only partially oxidized. It is decorated with $\mathrm{Mn}_{2} \mathrm{SiO}_{4}$ oxides in a facetted arrangement as shown in the insert of the right image.

SEM observations and EDX analysis confirm the XPS results. The sample annealed at $850^{\circ} \mathrm{C}$ show a strongly oxidized surface with 2 different types of oxide: large lenticular oxides $\left(\mathrm{Mn}_{2} \mathrm{SiO}_{4}\right)$ and veined oxide films $\left(\mathrm{SiO}_{2}\right)$. All the grain boundaries are strongly oxidized and contain high levels of $\mathrm{SiO}_{2}$ (black lines in the SE image of Figure 3).

On large areas of the samples annealed at $950^{\circ} \mathrm{C}$ no visual oxides could be detected. Some grains present larger lens-shaped $\mathrm{Mn}_{2} \mathrm{SiO}_{4}$ oxides but most grains are decorated with small globular oxides and exhibit a certain faceting typical for each (sub)grain. The grain boundaries are still strongly oxidized but also contain these small oxides apart from the $\mathrm{SiO}_{2}$ film.

From the XPS and SEM-EDX analysis it can be concluded that the surface after isothermal annealing is almost completely covered with an oxide film at both temperatures. At $850^{\circ} \mathrm{C}$ the film is thick, mainly composed of $\mathrm{SiO}_{2}$ and several lenticular $\mathrm{Mn}_{2} \mathrm{SiO}_{4}$ oxides have grown on top of it. At $950^{\circ} \mathrm{C}$ the oxide film is very thin and the surface is decorated with small globular $\mathrm{Mn}_{2} \mathrm{SiO}_{4}$ oxides.

\section{Low heating rate interrupted annealing}

Low heating rate interrupted annealing tests have been performed to evaluate the evolution of the surface oxidation during the heating stage. Figure 4 shows the $\mathrm{Fe}, \mathrm{Mn}$ and $\mathrm{Si}$ spectra at different stages during the slow heating. The quantification results for these spectra are presented in Figure 5. Only the samples heated to a temperature of $850^{\circ} \mathrm{C}$ and higher have been analyzed after air exposure. As the Si2p spectrum showed a double peak configuration, the spectrum was decomposed in a peak at $104 \mathrm{eV}$ and a peak at $102.5 \mathrm{eV}$, ascribed to $\mathrm{SiO}_{2}$ and $\mathrm{Mn}_{2} \mathrm{SiO}_{4}$ respectively. 

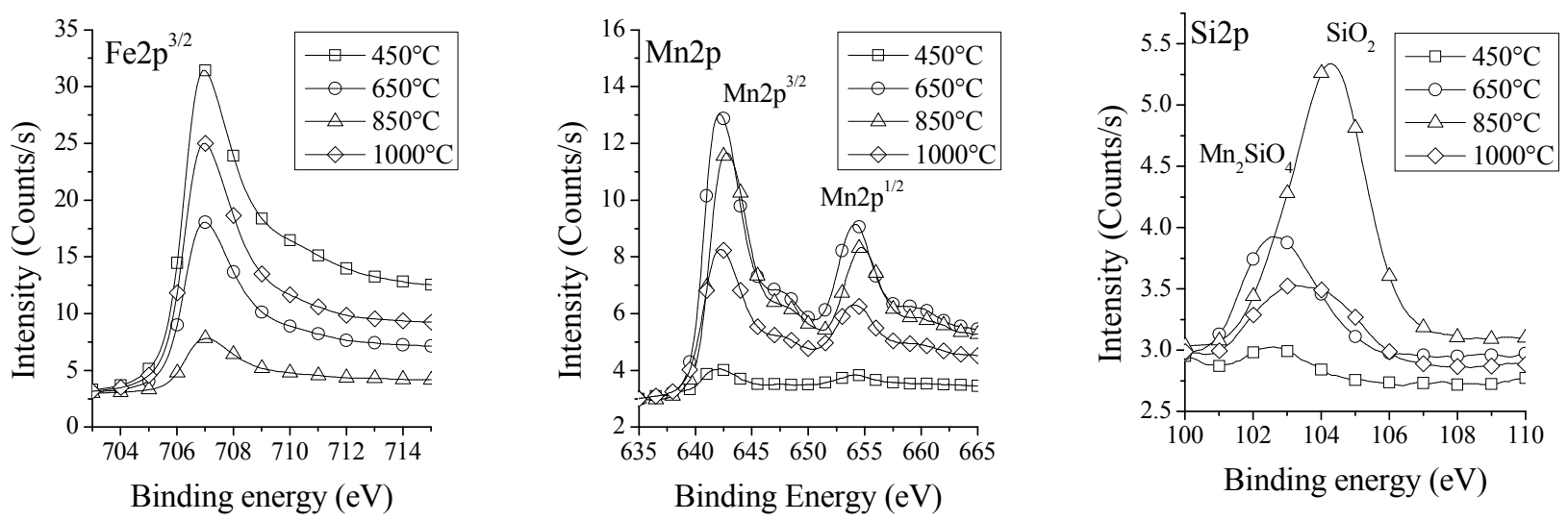

Figure 4: Fe, Mn and Si XPS spectra after in-situ interrupted annealing to various temperatures (heating rate of $6^{\circ} \mathrm{C} / \mathrm{s}$ ) in an $\mathrm{N}_{2}-5 \% \mathrm{H}_{2}$ atmosphere with a dew point of $-50^{\circ} \mathrm{C}$.

At $450^{\circ} \mathrm{C}$ the iron at the steel surface is completely reduced and there is almost no selective oxidation of $\mathrm{Si}$ and $\mathrm{Mn}$. After heating to $650^{\circ} \mathrm{C}$ there is still a lot of metallic iron present at the surface but the selective oxidation has started. The first oxide growing on the surface has a large $\mathrm{Mn}$ concentration. At temperatures above $650^{\circ} \mathrm{C}$, selective oxidation of silicon becomes predominant. At $850^{\circ} \mathrm{C}$ the iron concentration reaches its lowest level. The surface is nearly completely covered with silicon oxide $\left(\mathrm{SiO}_{2}\right)$ at this temperature. As the temperature further increases, more iron appears back at the surface and the amount of selective oxidation decreases. The amount of $\mathrm{SiO}_{2}$ drops while $\mathrm{Mn}_{2} \mathrm{SiO}_{4}$ oxides start to grow. The percentage of metallic iron that was oxidized after air exposure increases from $3.5 \%$ to $60 \%$ by increasing the heating temperature from $850^{\circ} \mathrm{C}$ to $1000^{\circ} \mathrm{C}$.
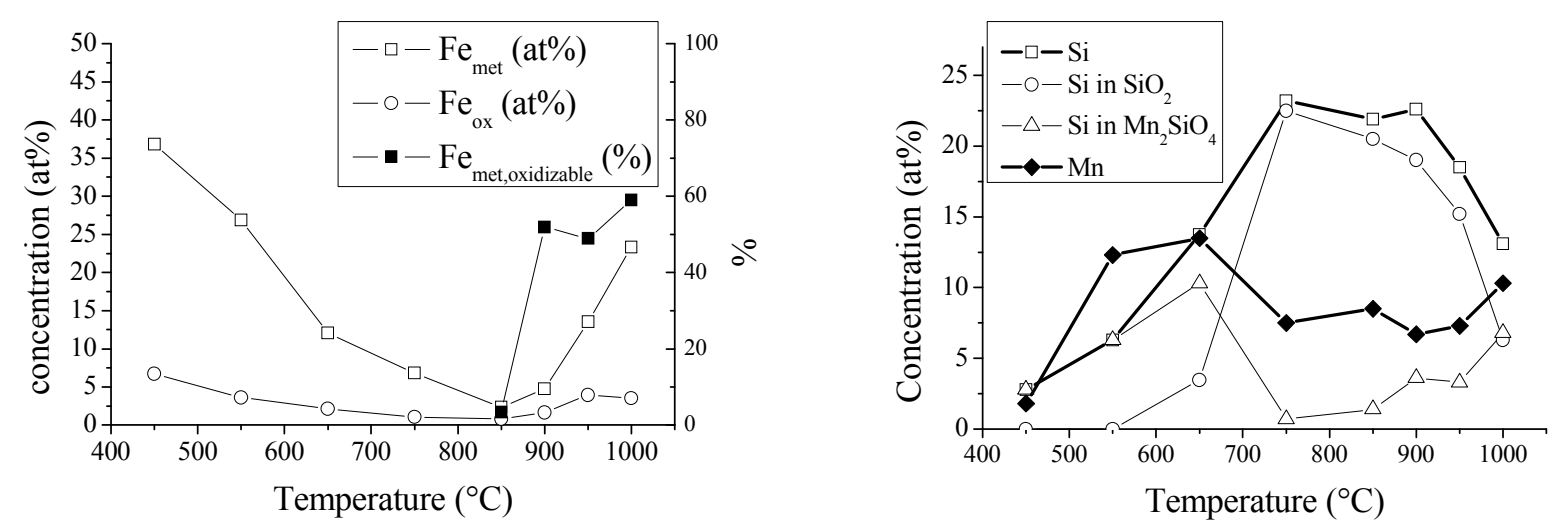

Figure 5: Quantification results of the in-situ XPS analysis after interrupted annealing of the industrial Si-TRIP steel. Atomic percentages of metallic and oxidized iron after heating and the calculated percentage of oxidizable metallic iron after air exposure (left). Atomic concentrations of Mn and $\mathrm{Si}$ in totality and in each compound (right).

\section{Discussion}

It seems rather contradictory that an increase of the annealing temperature causes a decrease of the selective oxidation. This is actually not in accordance with the Wagner theory [8] for selective oxidation that predicts a stronger external oxidation on increasing temperature. Due to the higher activation energy for diffusion of $\mathrm{Si}$ and $\mathrm{Mn}$ compared to oxygen, the outward flux of oxidizable elements will increase faster than the inward flux of oxygen with increasing temperature [9].

Assumptions can be made about the change in oxidation state on increasing the annealing temperature above $850^{\circ} \mathrm{C}$ but none of them are yet certified. 
One possibility is the transformation of the $\mathrm{SiO}_{2}$ oxide film into lenticular $\mathrm{Mn}_{2} \mathrm{SiO}_{4}$ oxides. Hereby a two dimensional $\mathrm{SiO}_{2}$ film is transformed in a 3 dimensional lenticular $\mathrm{Mn}_{2} \mathrm{SiO}_{4}$ oxide. Since the latter has a smaller surface area for the same amount of $\mathrm{Si}$ then in a $\mathrm{SiO}_{2}$ film, this transformation can cause the decreasing XPS signal of Si. It might also cause the increasing Fe concentration as a part of the surface becomes uncovered by $\mathrm{SiO}_{2}$ through this transformation. Upon prolonged annealing however this new metallic iron surface is not recovered by a thick $\mathrm{SiO}_{2}$ film. It is probably recovered by a very thin $\mathrm{Al}_{2} \mathrm{O}_{3}$ film.

On the other hand, it is rather strange that the change in oxidation behaviour coincides with the austenite transformation of a carbon depleted surface. Therefore an other possibility for the decrease of selective oxidation can be found in the decrease of the diffusion coefficients for $\mathrm{Si}, \mathrm{Mn}$ and $\mathrm{O}$ by the transformation. Hereby, the decrease of the diffusion coefficients of $\mathrm{Si}$ and $\mathrm{Mn}$ is much higher than for oxygen, slowing down the Si and Mn surface enrichment. Furthermore the appearance of new austenite glissile planes at the surface can cause an increase of the iron concentration and a breakdown of surface oxides.

\section{Conclusions}

The selective oxidation during recrystallization annealing of a $\mathrm{Si}$ and $\mathrm{Mn}$ alloyed high strength steel is investigated in a reducing $\mathrm{N}_{2}-5 \% \mathrm{H}_{2}$ atmosphere with a dew point of $-50^{\circ} \mathrm{C}$.

It is shown that annealing into the austenitic region decreases the amount of surface selective oxidation of $\mathrm{Si}$ and $\mathrm{Mn}$ for this steel type. The amount of metallic iron at the surface decreases between $450^{\circ} \mathrm{C}$ and $850^{\circ} \mathrm{C}$ during the heating stage of the continuous annealing cycle. When heated above $850^{\circ} \mathrm{C}$, the amount of metallic iron starts to increase again at the expense of the amount of selective oxides. The change in oxidation state can be explained by different effects; a structural transformation of the oxide layer or a substrate transformation induced effect. The amount metallic iron at the steel surface available for the formation of the inhibition layer in the zinc bath, called oxidizable iron is measured. It increases with temperature above $850^{\circ} \mathrm{C}$ during the heating stage. Upon soaking however the surface was again covered by a very thin oxide layer.

\section{References}

[1] J.Mahieu, S. Claessens and B.C. De Cooman: Metall. And Materials Trans. A, 2001, 32A, pp. 2905-2908.

[2] J. Mahieu, S. Claessens and B.C. De Cooman: In Galvatech '01 Conference Proceedings, Brussels, 2001, pp. 644-651

[3] P. Drillet, Z. Zermout, D. Bouleau, J. Mataigne, S. Claessens : In Galvatech '04 Conference Proceedings, Chicago, 2004, pp. 1123-1134.

[4] X. Vanden Eynde, J.P. Servais, L. Bordignon and M. Lamberigts: In Galvatech '01 Conference Proceedings, Brussels, 2001, pp. 187-194.

[5] X. Vanden Eynde, J.P. Servais, M. Lamberigts: In Galvatech '04 Conference Proceedings, Chicago, 2004, pp. 361372.

[6] J. Mahieu, S. Claessens, B.C. De Cooman and F. Goodwin :In Galvatech '04 Conference Proceedings, Chicago, 2004, pp. 529-538.

[7] X. Vanden Eynde, J.P. Servais, M. Lamberigts: Surf. Interface Anal. 2002, 33, pp. 322-329.

[8] C. Wagner: Zeitschrift für Electrochemie, 63 (7), 1959, pp. 772-782.

[9] J.M. Mataigne, M. Lamberigts, V. Leroy : Developments in the annealing of sheet steels, Edited by Pradhan and I. Gupta, The minerals, Metals and Materials Society, 1992, pp.511528. 